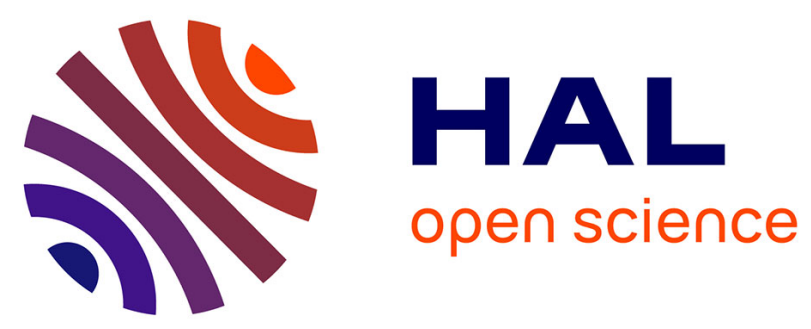

\title{
Hollow Beta Zeolite Single Crystals for the Design of Selective Catalysts
}

\author{
A. Prates, C. Pagis, Frédéric Meunier, L. Burel, T. Epicier, Lucian Roiban, S. \\ Koneti, Nicolas Bats, D. Farrusseng, A. Tuelt
}

\section{- To cite this version:}

A. Prates, C. Pagis, Frédéric Meunier, L. Burel, T. Epicier, et al.. Hollow Beta Zeolite Single Crystals for the Design of Selective Catalysts. Crystal Growth \& Design, 2018, 18 (2), pp.592-596. 10.1021/acs.cgd.7b01635 . hal-01719800

\section{HAL Id: hal-01719800 https://hal.science/hal-01719800}

Submitted on 23 Jul 2018

HAL is a multi-disciplinary open access archive for the deposit and dissemination of scientific research documents, whether they are published or not. The documents may come from teaching and research institutions in France or abroad, or from public or private research centers.
L'archive ouverte pluridisciplinaire HAL, est destinée au dépôt et à la diffusion de documents scientifiques de niveau recherche, publiés ou non, émanant des établissements d'enseignement et de recherche français ou étrangers, des laboratoires publics ou privés. 


\title{
Hollow Beta zeolite single crystals for the design of selective catalysts
}

\author{
Ana Rita Morgado Prates ${ }^{\mathrm{a}}$, Céline Pagis ${ }^{\mathrm{a}, \mathrm{c}}$, Frederic C. Meunier ${ }^{\mathrm{a}}$, Laurence Burel ${ }^{\mathrm{a}}$, Thierry Epicier ${ }^{\mathrm{b}}$, Lu- \\ cian Roiban $^{\mathrm{b}}$, Siddhardha Koneti ${ }^{\mathrm{b}}$, Nicolas Bats ${ }^{\mathrm{c}}$, David Farrusseng*a, Alain Tuel ${ }^{\mathrm{a}}$
}

aIRCELYON, 2 avenue Albert Einstein, 69626 Villeurbanne Cedex

bUniv. Lyon, INSA-Lyon, Université Claude Bernard Lyon 1, MATEIS, UMR 5510, CNRS, 7 avenue Jean Capelle, 69621

Villeurbanne Cedex, France

cIFP Energies Nouvelles, Rond-point de l'échangeur de Solaize, BP3, F-69360 Solaize, France

\section{Supporting Information Placeholder}

\begin{abstract}
We present a Pt@Beta catalyst with a unique, well-controlled location of metal nanoparticles that allows more efficient use of this rare, expensive metal in catalysis. The zeolite crystal has an inner cavity, leaving a thin zeolite shell where the metal nanoparticles are encapsulated, thereby ensuring a relatively small diffusional path length and high selectivity. Hollow Beta is obtained by a controlled dissolutionrecrystallization method. The location of the particles was not only revealed by electron tomography 3D reconstruction but was further confirmed by a model hydrogenation reaction of aromatics.
\end{abstract}

Zeolites are microporous materials with molecular sized pore dimensions ${ }^{1}$. Thanks to chemical and physical properties of these aluminosilicate crystals, zeolites have been widely used in petrochemical and oil refining industry as catalysts, adsorbents and molecular sieves. ZSM5, Y and Beta zeolites with MFI, FAU and *BEA framework topologies, respectively, are amongst the most studied ones ${ }^{2}$. In particular, *BEA is a large pore zeolite, that can be easily synthesized with different Al contents, which makes this zeolite particularly attractive as catalyst in petrochemical industry. ${ }^{3}$

The diffusion of molecules through the microporous network of the zeolite can be extremely slow, which would tend to reduce reaction rates and the useful fraction of crystals for catalysis, i.e., the volume of zeolite that is actually used ${ }^{4}$. In the case of zeolites containing precious group metal (PGM) within the zeolite framework, the result is that a considerable fraction of expensive metal is wasted ${ }^{5}$.

New classes of zeolite crystal morphologies have been developed in order to decrease transport limitations: zeolites with a shorter critical length such as nanosized zeolites ${ }^{6,7}$, or hierarchical micro-mesoporous zeolite, in which the mesopores work as "molecular highways" both approaches, the diffusional path length is smaller, which is as expected. Conversely, the external surface increases, usually in association with the mesoporous specific surface area. Hollow zeolite single crystals are a new class of zeolite morphology consisting in a bulk zeolite containing a very large inner cavity ${ }^{9}$. The morphology of hollow single crystal zeolites departs from nanosized and hierarchical porous zeolites because the critical length (which corresponds to the shell thickness) is reduced while the external surface remains the same (Figure 1e). Note that state-of-the-art hollow zeolites are generally made of an aggregation of small seed crystals (Figure 1d) resulting in a polycrystalline micro-mesoporous shell. 9,10

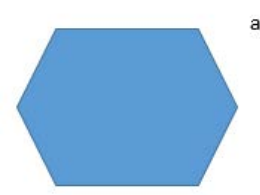

a)

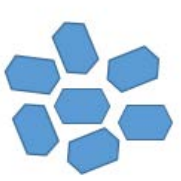

b)
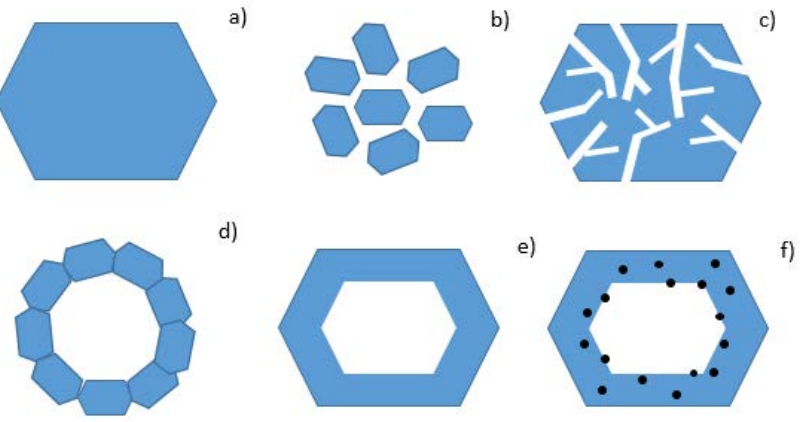

Figure 1 - a) bulk zeolite, b) nanozeolites, c) hierarchical porous zeolite, d) hollow polycrystalline zeolite, e) hollow zeolite single crystal, and f) metal nanoparticles encapsulated within a hollow zeolite single crystal. 
There are several protocols for encapsulating metal nanoparticles within zeolites while leaving no nanoparticles on the external surface of the crystal ${ }^{5,11-13}$. This encapsulation approach has been shown to be particularly efficient against sintering by coalescence, while improving reaction selectivity ${ }^{14}$. In cases with fast reaction kinetics, we can assume that the nanoparticles located in the center of the crystal do not participate in the catalytic conversion because of internal diffusion limitations. Therefore, the effectiveness factor is impaired ${ }^{15}$. A catalyst that would not contain metal nanoparticles too far away from the surface or in the center of the crystal would be an appropriate design to address the waste of expensive metals. Nonetheless, to the best of our knowledge, the synthesis of encapsulated nanoparticles with such a spatial gradient has not been achieved. Encapsulating metal nanoparticles within a hollow zeolite single crystal (Figure 1f) provides an alternative design in which all nanoparticles are located close to the surface as compared to a bulk crystal with nanoparticles encapsulated throughout the entire volume of the crystal. So far, only metal nanoparticles encapsulated in hollow MFI single crystals have been reported ${ }^{5,16}$. As expected, these catalysts have shown remarkable size- and diffusion-driven selectivity as well as sintering resistance. ${ }^{9,15-17}$ In the case of the hydrogenation of toluene on Pt nanoparticles encapsulated in an extremely thin zeolite shell, the effectiveness factor was demonstrated to have reached $100 \%$ versus $10 \%$ for the corresponding classic bulk impregnated zeolite ${ }^{15}$.

The formation of the hollow zeolite single crystal requires a bulk crystal with a spatial concentration gradient, for example $\mathrm{Al}$ zoning, in which the center of the crystal is richer in Si and can be preferentially removed by desilication, leaving a hollow zeolite structure. ${ }^{18}$ Such a spatial gradient with an Al-rich surface is generally observed in ZSM-5 crystals prepared with TPA ${ }^{+}$cations as the template, but as far as we are concerned, it is not usually observed for other zeolites, such as *BEA. A typical alkaline desilication treatment over Beta zeolite creates a disorganized mesoporous pore system, but not an internal cavity ${ }^{4}$.

For a ZSM-5 with such an Al-rich surface, the treatment with an alkaline reagent such as $\mathrm{Na}_{2} \mathrm{CO}_{3}$ solution generates an inner cavity thanks to the selective desilication of the center of the crystal. Alternatively, desilication can also be performed with alkaline TPAOH solution at higher temperatures, which enables not only the desilication of the center but also the recrystallization of the dissolved species on the outer surface of the crystal (dissolution-recrystallization method), thereby improving the regularity of the zeolite walls. ${ }^{15}$ The latter method is very appropriate for the encapsulation of nanoparticles inside the inner cavity ${ }^{5}$.

To the best of our knowledge, hollow Beta zeolite single crystals with encapsulated nanoparticles have never been reported. Indeed, in the case of Beta zeolite, the absence of $\mathrm{Al}$ zoning (or of any other property with a spatial gradient) prohibits the use of the dissolution-recrystallization strategy employed in the synthesis of the aforementioned hollow zeolite single crystals with encapsulated nanoparticles.

Herein, we present the synthesis of hollow Beta zeolite single crystals (Pt@Beta) in which Pt nanoparticles are encapsulated in the cavity and inside the zeolite shell. The Pt nanoparticles are demonstrated to be accessible only through the *BEA zeolite by means of a model catalytic hydrogenation test. The novel synthesis consists indeed in a dissolution-recrystallization process, but over CIT-6 (zincosilicate with *BEA structure) containing Pt nanoparticles, instead of using the same bulk crystal type, as in the methods presented before for MFI zeolite. In this final step, Beta zeolite is formed during the recrystallization stage around the CIT-6 surface, which is subsequently dissolved (Figure 2).

The synthesis of Pt@Beta is inspired by a seed-assisted synthesis approach described by the literature ${ }^{19}$, which used CIT-6 crystals as Beta seeds (Figure 2).

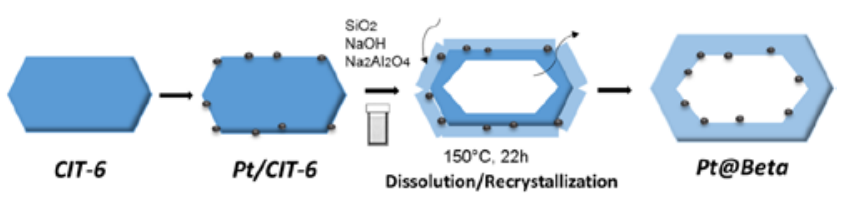

Figure 2 - Multistep synthesis of Pt@Beta starting from CIT-6

CIT-6 is a zincosilicate microporous material with the same *BEA framework topology as Beta. The preparation of the CIT-6 crystals is performed according to a procedure described in the literature ${ }^{20}$. A synthesis mixture is prepared with the following composition: $\mathrm{SiO}_{2}: 0.05$ $\mathrm{LiOH}: 0.65$ TEA : $0.03 \mathrm{Zn}\left(\mathrm{CH}_{3} \mathrm{CO}_{2}\right)_{2}: 30 \mathrm{H}_{2} \mathrm{O}$ (check Supplementary information for more details). After preparing an aqueous solution of $\mathrm{LiOH}, \mathrm{TEAOH}$ and $\mathrm{Zn}\left(\mathrm{CH}_{3} \mathrm{CO}_{2}\right)_{2}$, Ludox $\mathrm{HS} 40$ colloidal silica is added dropwise. The resulting mixture is stirred for $1 \mathrm{~h}$ at $40^{\circ} \mathrm{C}$, to yield a clear solution. Crystallization is performed in a $48 \mathrm{ml}$ Teflon-lined stainless-steel autoclave, under static conditions at $145^{\circ} \mathrm{C}$ for 4 days. The X-ray powder diffractogrammes of the as-synthesized samples show a typical *BEA pattern as expected, with neither impurities nor other crystalline phases (see Figure S1). SEM images of bulk CIT-6 crystals show a homogeneous distribution of crystals with tetragonal pyramidal morphology and sizes between 0.5 and $1.1 \mu \mathrm{m}$ (Figures 3a and S2.

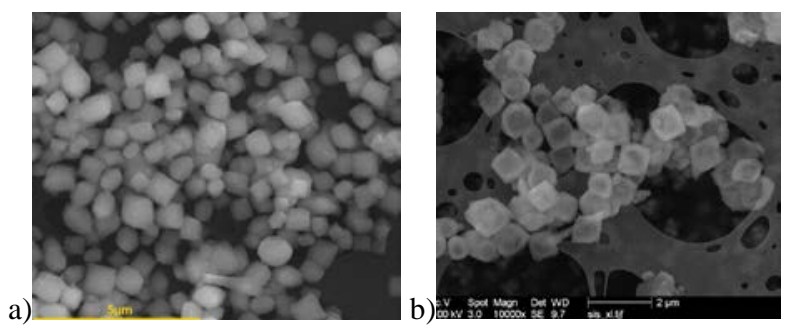

Figure 3 - SEM images of bulk CIT-6 crystals (on the left) and Pt@Beta crystal (on the right). Because these samples were not coated with a metal layer, as in classic SEM sample preparation, one can obtain information on the inside of the crystals. The white/grey color depends on the density of atoms perceived by the electon beam, and therefore the number of electrons detected. This contrast directly informs on the hollow nature of the crystals. 
As a second step of the process, these as-made bulk zincosilicate CIT-6 crystals are impregnated with a Pt precursor solution and then reduced by a $\mathrm{NaBH}_{4}$ solution. This sample is referred to as Pt/CIT-6. XRD results show that after impregnation, Pt/CIT-6 is highly crystalline. The two small peaks at $40^{\circ}$ and $46^{\circ}$ for Pt/CIT- 6 are attributable to platinum nanoparticles; ICP analysis reveals a final Pt content of 2.6 wt.\%. The location and size of platinum nanoparticles impregnated on the surface of CIT-6 were investigated by TEM (Figure S3), which shows that the platinum nanoparticles (particle size between $\sim 10-20 \mathrm{~nm}$ ) are successfully anchored on the external surface of the crystals. Nitrogen adsorption/desorption (77 K) performed on the calcined Pt/CIT-6 solid presents a type I isotherm typical of a purely microporous crystal (Figure S8).

As described before, in the case of hollow MFI crystals with encapsulated nanoparticles, the impregnation is carried out on the calcined bulk MFI crystals, followed by an $\mathrm{H}_{2}$ reduction, and finally the dissolution-recrystallization method to create the cavity. This process, however, cannot be applied to the CIT-6 crystals. Actually, if CIT-6 crystals are calcined before the hollow Beta synthesis, the CIT-6 is dissolved during the hydrothermal treatment before any Beta crystallization can occur on its surface. As-made CIT-6 crystals containing the organic template present the advantage of being more stable in alkaline medium, thereby allowing the crystallization of Beta zeolite on the surface before its complete dissolution.

$\mathrm{Pt} @$ Beta is obtained by hydrothermal treatment of the as-made Pt/CIT-6 in the presence of an organic-free aluminosilicate gel (SiO 2 : $0.01 \mathrm{Al}_{2} \mathrm{O}_{3}: 0.3 \mathrm{NaOH}: 20 \mathrm{H}_{2} \mathrm{O}$ ) in which CIT-6 represents $10 \mathrm{wt} \%$ of the total amount of silica source. Firstly, an aqueous solution of $\mathrm{NaOH}$ and $\mathrm{NaAlO}_{2}$ is prepared. Then, CIT-6 crystals are added to the solution, which is gently stirred until the dispersion becomes homogeneous. Finally, Aerosil 200 is slowly added with vigorous stirring. The hydrothermal treatment is performed at $150{ }^{\circ} \mathrm{C}$ for $22 \mathrm{~h}$. During this time, Beta zeolite starts to recrystallize on the CIT-6 surface, which afterward is dissolved, leading to hollow single crystals.

As revealed by XRD and electron microscopy images (Figures S1, S2, S4, and Figure 3b and Figure 4), after hydrothermal treatment a highly crystalline hollow Beta crystal is obtained, in which the Pt nanoparticles are encapsulated inside the cavity and/or in the zeolite shell. The Pt@Beta presents a crystal size between 0.6 and $1.2 \mu \mathrm{m}$. The size of the cavity corresponds approximately to that of the dissolved CIT6 crystal, leaving an average shell thickness of $90-190 \mathrm{~nm}$. The observed crystal shape is a truncated tetragonal pyramidal morphology, pine tree shaped on each sides, which is typical for Beta zeolite crystal morphology ${ }^{4}$.

HRTEM images and STEM images over sliced hollow Beta crystals also clearly reveal the presence of mesopores in the internal part of the microporous wall (see Figure S6) with an average size between $\sim 5$ and $15 \mathrm{~nm}$. Nonetheless, it must be noted that the external part of the hollow zeolite is entirely microporous, because the mesopores are not connected to the external surface. The homogeneity of the synthesis can be validated by SEM observations (Figure 3b and Figure S2). Specific sample preparation was used to highlight the hollow nature of the crystals (SI). When comparing SEM images of bulk CIT-6 and hollow *BEA under identical conditions, it is obvious that all *BEA crystals possess a large internal cavity, as evidenced by the contrast between the center and extremities of the crystal.

The $\mathrm{N}_{2}$ physisorption isotherm of Pt@Beta at $77 \mathrm{~K}$ (Figure S7) presents a type I adsorption branch at low pressure, which is typical of a microporous material, and a type IV branch with a hysteresis that closes at $\mathrm{p} / \mathrm{p}^{\circ}=0.53$, which can be associated with condensation phenomena in bottle-neck pores ${ }^{21-23}$. Indeed, as mentioned above, HRTEM and STEM images over sliced hollow Beta crystals clearly show the presence of mesopores in the internal part of the microporous wall (see Figure S6). These results show that this material consists of a hollow single crystal in contrast to a polycrystalline aggregation such as published elsewhere ${ }^{24}$.

Chemical analysis of the Pt@Beta crystals gives Si/Al and Si/Zn molar ratios of 8 and 237, respectively. The remaining Zn concentration is very low, clearly indicating that the dissolution of CIT-6 during the hydrothermal treatment is almost complete. The remaining fraction of $\mathrm{Zn}$ could result from $\mathrm{Zn}$ species reincorporated either in the hollow Beta framework or in the pores as extra-framework species to compensate for the charge of the aluminum atoms.

The Pt loading on the Pt@Beta is 1 wt.\%, and its dispersion is around 3\%, as calculated from the particle size distribution determined from TEM images.

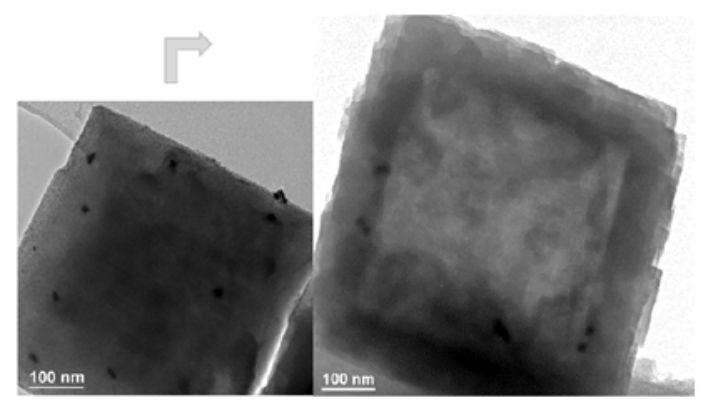

Figure 4 - TEM images of Pt/CIT-6 (left) and Pt@Beta zeolite with Pt nanoparticles encapsulated inside the wall and inside the cavity (right).

TEM observations over a large population of Pt@Beta crystals,_consistently show the presence of Pt NPs inside each crystal, and the absence of visible Pt NPs on the external border of the crystals, (see Figure 4 and Figure S4 for example). This is an evidence of the internal location of the Pt NPs. Transmission electron tomography with corresponding 3D reconstruction was carried out on an isolated hollow crystal, confirming the absence of visible Pt nanoparticles on the external surface (Figure 5 and Figure S7). On the other hand, the nanoparticles are clearly observed on the inner surface of the cavity, and inside the zeolite wall, in the mesoporous region, with an average diameter of $28 \mathrm{~nm}$ (Figure 5-b). 

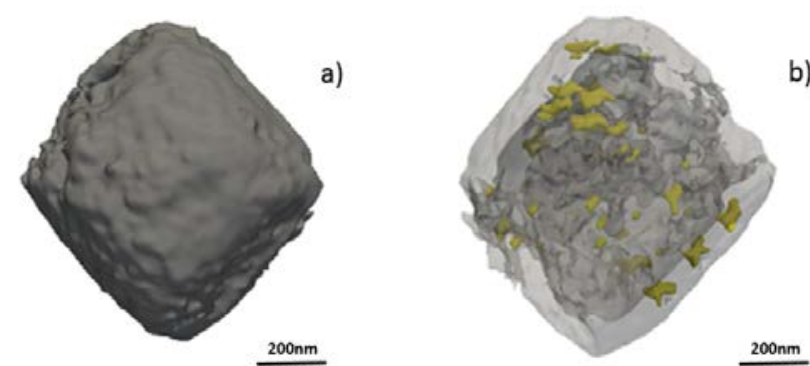

Figure 5 - 3D models of a Pt@Beta zeolite crystal reconstructed from electron tomography. The zeolite is represented in grey and Pt nanoparticles are represented in yellow. External view (left), transparent view (right).

Pt@Beta crystal show to be resistant to calcination at $750^{\circ} \mathrm{C}$ for 10 hours. The particle size distribution of the Pt NPs remains very similar regarding the as-made Pt@Beta (Figure S4 and S5).

The location of the nanoparticles inside the wall and cavity was also confirmed by a model hydrogenation reaction using reactants with different diffusion rates. The catalytic hydrogenations of toluene and mesitylene were chosen as model reactions to demonstrate that there are no particles at the zeolite surface. Toluene and mesitylene hydrogenations were carried out using a tubular quartz plug flow reactor placed in a tubular furnace at atmospheric pressure. A mass of $10 \pm 0.1 \mathrm{mg}$ of catalyst, held between quartz wool plugs, was used. Each substrate was fed separately using a saturator maintained at $0{ }^{\circ} \mathrm{C}$ for toluene and $17{ }^{\circ} \mathrm{C}$ for mesitylene, leading to partial pressures of $0.91 \mathrm{kPa}$ and $0.20 \mathrm{kPa}$, respectively. The reactor effluent was analyzed in a 10-cm path length gas cell fitted in a Bruker Tensor 27 FT-IR spectrophotometer. The activity of Pt@Beta in the hydrogenation of these two substrates was compared with that obtained over a conventional Pt catalyst supported on silica $\left(\mathrm{Pt} / \mathrm{SiO}_{2}\right)$, for which all $\mathrm{Pt}$ nanoparticles are accessible without any diffusion constraints (Figure 6). The Pt/SiO ${ }_{2}$ data were reported in an earlier paper ${ }^{16}$ and are reused here for the sake of comparison.

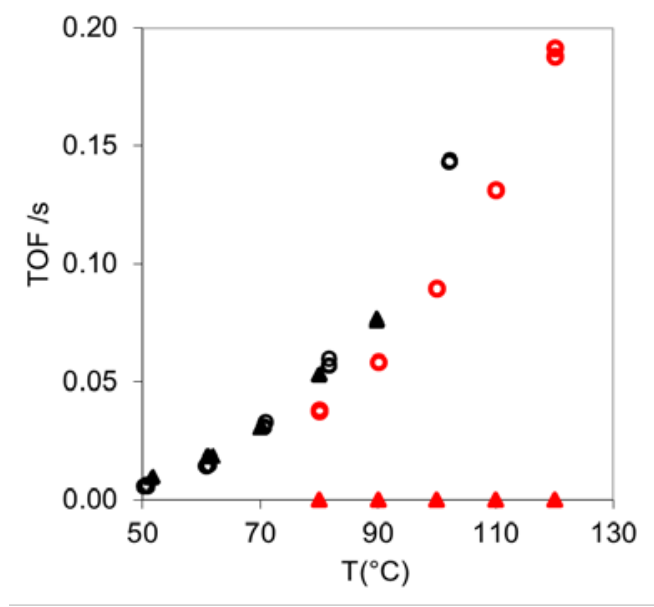

Figure 6 - Activity (turnover frequency) of $\mathrm{Pt} / \mathrm{SiO}_{2}$ catalyst (black symbols) and Pt@Beta catalyst (red symbols), in the hydrogenation of toluene (circles) and mesitylene (triangles). Toluene pressure $=0.9 \mathrm{kPa}$, balance $\mathrm{H}_{2}$. Mesitylene pressure $=0.06 \mathrm{kPa}$ and $0.2 \mathrm{kPa}$, for Pt/SiO${ }_{2}$ and $\mathrm{Pt} @ \mathrm{Beta}$ respectively, balance $\mathrm{H}_{2}$.

The $\mathrm{Pt} / \mathrm{SiO}_{2}$ catalyst was active for the hydrogenation of both toluene and mesitylene, showing very similar turnover frequencies (Figure 6). The turnover frequency and apparent activation energy values (e.g., TOF $\mathrm{Pt}_{\mathrm{S} / \mathrm{SiO} 2}=6 \mathrm{x} 10^{-2} \mathrm{~s}^{-1}$ at $80{ }^{\circ} \mathrm{C}$ and $55 \pm 3 \mathrm{~kJ} / \mathrm{mol}$ for toluene, Figure S11) are consistent with the literature data for both reactions ${ }^{16}$.

Catalytic activity of Pt@Beta for toluene hydrogenation shows similar TOF values to those observed in the case of $\mathrm{Pt} / \mathrm{SiO} 2$ (e.g., at 80 ${ }^{\circ} \mathrm{C}$, TOF Pt@Beta $\left.=4 \times 10^{-2} \mathrm{~s}^{-1}\right)$. Similarly, the value for the apparent reaction activation energy $\left(\mathrm{E}_{\mathrm{a}}=47 \mathrm{~kJ} / \mathrm{mol}\right)$ is consistent with those reported in the literature for $\mathrm{Pt} / \mathrm{SiO}_{2}{ }^{16,25}$ (Figure S10). On the other hand, mesitylene conversion was negligible (conversion in the error range of ca. $0.01 \%$ ), and the corresponding TOF is therefore essentially nil over Pt@Beta, in contrast to Pt/SiO ${ }_{2}$. Even though the mesitylene pressure used was slightly different for the two catalysts, this should not affect the TOF values since the reaction order with respect to the aromatic on Pt-based catalysts is typically zero or close to zero ${ }^{25,26}$.

The TOF values of $\mathrm{Pt} / \mathrm{SiO}_{2}$ and $\mathrm{Pt} @$ Beta are similar. Based on our latest studies ${ }^{15,16}$, we can rationalize that no significant diffusional limitation occurs in the toluene hydrogenation (i.e., effectiveness is high) thanks to the small shell thickness. In contrast, we can conclude that severe diffusional limitation occurs for the bulkier mesitylene for Pt@Beta. Although mesitylene is able to enter into the *BEA pore system, its diffusion in the microporous framework is significantly slower than that of toluene due to its larger kinetic diameter, which is $0.86 \mathrm{~nm}$ compared to $0.61 \mathrm{~nm}$ for toluene (Figures S12- S13). The fact that toluene (but not mesitylene) is readily hydrogenated clearly demonstrates the absence of nanoparticles on the external surface. It also evidences the single crystal nature of this material, as well as the absence of a mesopore network connecting the external surface and the inner cavity. A mesopore system would allow the diffusion of mesitylene through the zeolite shell, and as consequence its hydrogenation. 
Herein we have presented a Pt@Beta catalyst with a unique, well-controlled location of metal nanoparticles in the zeolite shell. This novel catalyst design makes it possible to use a greater portion of metals involved in the catalytic reaction, reducing the waste of expensive metals and improving the effectiveness factor.

\section{ASSOCIATED CONTENT}

\section{Supporting Information}

The Supporting Information is available free of charge on the ACS Publications website.

Information on synthesis, XRD, SEM, TEM, $\mathrm{N}_{2}$ isotherms, toluene and mesitylene adsorption isotherms, catalytic tests, FT-IR transmission spectra, Arrhenius-type plot of catalytic results.

\section{AUTHOR INFORMATION}

\section{Corresponding Author}

david.farrusseng@ircelyon.univ-lyon1.fr

\section{Notes}

The authors declare no competing financial interests.

\section{Acknowledgements}

The authors would like to thank Cecile Daniel for the scientific services provided for this study.

The authors would like to thank CLYM (Centre Lyonnais de Microscopie) for granting access to the FEI ETEM Titan 300-80 keV and Jeol 2100F.

\section{REFERENCES}

(1) Maria Gallego, E.; Teresa Portilla, M.; Paris, C.; Leon-Escamilla, A.; Boronat, M.; Moliner, M.; Corma, A. Science 2017, 355, $1051-1054$.

(2) Vermeiren, W.; Gilson, J.-P. Top. Catal. 2009, 52, 1131-1161.

(3) Martinez-Franco, R.; Paris, C.; Martinez-Armero, M. E.; Martinez, C.; Moliner, M.; Corma, A. Chem. Sci. 2016, 7, $102-108$.

(4) Groen, J. C.; Abello, S.; Villaescusa, L. A.; Pérez-Ramirez, J. Microporous Mesoporous Mater. 2008, 114, 93-102.

(5) Farrusseng, D.; Tuel, A. New J Chem 2016, 40, 3933-3949.

(6) Larlus, O.; Mintova, S.; Wilson, S. T.; Willis, R. R.; Abrevaya, H.; Bein, T. Microporous Mesoporous Mater. 2011, $142,17-25$.

(7) Awala, H.; Gilson, J.-P.; Retoux, R.; Boullay, P.; Goupil, J.-M.; Valtchev, V.; Mintova, S. Nat. Mater. 2015, 14, 447-451.

(8) Verboekend, D.; Mitchell, S.; Pérez-Ramirez, J. Chim. Int. J. Chem. 2013, 67, 327-332.

(9) Pagis, C.; Morgado Prates, A. R.; Farrusseng, D.; Bats, N.; Tuel, A. Chem. Mater. 2016, 28, 5205-5223.

(10) Valtchev, V.; Mintova, S. Microporous Mesoporous Mater. 2001, 43, 41-49.

(11) Tahri, Z.; Luchez, F.; Yordanov, I.; Poizat, O.; Moissette, A.; Valtchev, V.; Mintova, S.; Mostafavi, M.; Waele, V. D. Res. Chem. Intermed. 2009, 35, 379-388.

(12) Oda, A.; Torigoe, H.; Itadani, A.; Ohkubo, T.; Yumura, T.; Kobayashi, H.; Kuroda, Y. J. Am. Chem. Soc. 2013, 135, $18481-18489$.

(13) Guczi, L.; Kiricsi, I. Appl. Catal. -Gen. 1999, 186, 375-394.

(14) Goel, S.; Zones, S. I.; Iglesia, E. J. Am. Chem. Soc. 2014, 136, 15280-15290.

(15) Li, S.; Tuel, A.; Meunier, F.; Aouine, M.; Farrusseng, D. J. Catal. 2015, 332, 25-30.

(16) Li, S.; Boucheron, T.; Tuel, A.; Farrusseng, D.; Meunier, F. Chem. Commun. 2014, 50, 1824.

(17) Li, S.; Tuel, A.; Laprune, D.; Meunier, F.; Farrusseng, D. Chem. Mater. 2015, 27, 276-282.

(18) Groen, J. C.; Bach, T.; Ziese, U.; Paulaime-van Donk, A. M.; de Jong, K. P.; Moulijn, J. A.; Pérez-Ramirez, J. J. Am. Chem. Soc. 2005, 127, 1079210793.

(19) Iyoki, K.; Itabashi, K.; Okubo, T. Chem. - Asian J. 2013, 8, 1419-1427.

(20) Takewaki, T.; Beck, L. W.; Davis, M. E. Top. Catal. 1999, 9, 35-42.

(21) Thommes, M.; Kaneko, K.; Neimark, A. V.; Olivier, J. P.; Rodriguez-Reinoso, F.; Rouquerol, J.; Sing, K. S. W. Pure Appl. Chem. 2015, 87, 10511069 .

(22) Thommes, M.; Cychosz, K. Adsorption 2014, 20, 233-250.

(23) Ravikovitch, P. I.; Neimark, A. V. Langmuir 2002, 18, 9830-9837.

(24) Zheng, Z.; Sun, C.; Dai, R.; Wang, S.; Wu, X.; An, X.; Xie, X. Catal. Sci. Technol. 2016, 6, 6472-6475.

(25) Rousset, J. L.; Stievano, L.; Aires, F. J. C. S.; Geantet, C.; Renouprez, A. J.; Pellarin, M. J. Catal. 2001, 197, $335-343$.

(26) Bond, G. C. Metal-Catalysed Reactions of Hydrocarbons; Fundamental and Applied Catalysis; Springer US, 2005. 


\section{For Table of Contents Use Only}

\section{Hollow Beta zeolite single crystals for the design of selective catalysts}

Ana Rita Morgado Prates ${ }^{\mathrm{a}}$, Céline Pagis ${ }^{\mathrm{a}, \mathrm{c}}$, Frederic C. Meunier ${ }^{\mathrm{a}}$, Laurence Burel ${ }^{\mathrm{a}}$, Thierry Epicier ${ }^{\mathrm{b}}$, Lucian Roiban $^{\mathrm{b}}$, Siddhardha Koneti ${ }^{\mathrm{b}}$, Nicolas Bats ${ }^{\mathrm{c}}$, David Farrusseng*a, ${ }^{*}$ Alain Tuel ${ }^{\mathrm{a}}$

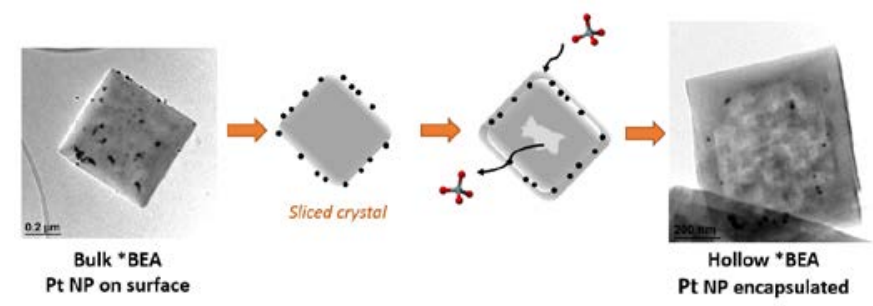

We present a Pt@Beta catalyst with a hollow morphology and encapsulated metal nanoparticles (NPs) inside the zeolite shell, ensuring a small diffusional path length and high selectivity. Materials were obtained by a controlled dissolution-recrystallization method. The location of the NPs was not only revealed by electron tomography 3D reconstruction but was further confirmed by a model hydrogenation reaction of aromatics. 